\title{
LeSSONS FROM SOUTH AFRICA's RenEWABLE Energy Regulatory and ProcuRement EXPERIENCE
}

\author{
Gaylor Montmasson-Clair* \\ Trade and Industrial Policy Strategies \\ Gaylor@tips.org.za
}

Received: June 2014

\author{
Georgina Ryan+ \\ Trade and Industrial Policy Strategies \\ Georgina@tips.org.za
}

Accepted: September 2014

\begin{abstract}
South Africa's Renewable Energy Independent Power Producer (REIPP) procurement programme is hailed worldwide as a model for renewable energy procurement. Its success is far from experimental and haphazard and points directly to lessons acquired prior to, and during, the launch and running of the programme. This article explores the journey to the REIPP procurement programme and draws critical lessons from the process. It discusses the success of the REIPP procurement programme in developing the renewable energy sector in South Africa, drawing seven key lessons explain this success and exploring the remaining challenges. The article shows that, despite the need for further improvements and continual optimisation, the development of the REIPP procurement programme has been a positive illustration of successful policy and regulatory learning processes
\end{abstract}

Keywords

Electricity, renewable energy, Independent Power Producers, procurement, economic regulation

*Mr G Montmasson-Clair is an Assistant Programme Manager: Sustainable Growth at Trade and Industrial Policy Strategies (TIPS); Research Fellow, Centre for Competition Regulation and Economic Development, University of Johannesburg, South Africa.

\#Ms G Ryan is a Junior Researcher: Sustainable Growth at Sustainable Growth at Trade and Industrial Policy Strategies (TIPS); Research Fellow, Centre for Competition Regulation and Economic Development, University of Johannesburg, South Africa. 


\section{INTRODUCTION}

As the world grapples with multiple crises on economic, social and environmental fronts, sustainable development, notably through the transition to a green economy, has been internationally acknowledged as the way forward. South Africa is in a unique position to benefit from the shift to a greener development path, owing to its abundance in renewable resources. Accordingly, the country has demonstrated an increasing commitment to sustainable development, especially in renewable energy.

The development of renewable energy in South Africa, which is strongly intertwined with the introduction of independent power producers (IPPs) onto the electricity market, results from four grand dynamics. First, the South African government recognises that Eskom alone does not have the financial and technical capacity to meet the country's electricity demand and ensure energy security. In 2003 government set the objective of deriving $30 \%$ of the new power generation capacity from private developers from renewable energy, but also from coal and gas (Steyn, 2013). Second, the development of renewable energy, along with the introduction of IPPs, aims to reduce the cost of electricity in South Africa, in the short term, through generation capacity built at the cost and financial risk of IPPs, and in the medium to long term, through the development of increasingly competitive and cost-effective renewable energy-based alternatives to traditional fuels and technologies (DoE, 2013a, 2011; IRENA, 2013a). The proposed carbon tax should also strengthen the business case for shifting to greener generation technologies. Third, renewable energy technologies, as clean, low-carbon options, form part of government's climate change mitigation and green economy strategies. Lastly, the creation of a renewable energy industry in the country is meant to support local economic development objectives, with the aim of contributing to the creation of 400000 new direct jobs by 2030 in green economy sectors, as targeted in the country's New Growth Path (EDD, 2010).

Against this background, South Africa's Renewable Energy Independent Power Producer (REIPP) procurement programme was launched in August 2011. The programme has been hailed worldwide as a model for renewable energy procurement (IRENA, 2013b; Eberhard, Kolker \& Leigland, 2014). Matching (if not setting) international guidelines, the current South African procurement programme is structured around the following best practice criteria: effective and efficient institutional coordination; coherence and certainty in the selected support scheme; flexibility provisions in the event of significant market changes or unintended consequences; centrality of the price mechanism; certainty on return on investment; coordination between all interest groups; development goals for rural and vulnerable populations; and regulatory principles of transparency, clarity and predictability (Bjork et al., 2014).

While the achievements of the programme have been extensively publicised, little research has been conducted on the political, policy and technical underpinnings of the current scheme. This success is indeed far from experimental and haphazard and points to a set of learnings and lessons acquired prior to, and during, the launch and running of the programme.

Exploring the journey to the REIPP procurement programme and drawing a series of critical learnings require a theoretical framing essentially oriented towards a delivery analysis framework, as conceptualised by Parsons (1995). Although it does cover issues of agenda definition and agenda setting (meso analysis) or questions around public choice (decision analysis), the analysis concentrates on the entire chain of implementation, including the choice of instruments and their application, evaluation, performance and revision (Lafferty, 2004). This 
approach provides the right focus to understand and analyse in detail the road to the current procurement programme and shed light on its foundations.

The methodological approach to exploring the development and progress of the renewable energy procurement programme draws on an analysis of South African government policy and its implementation from the mid-1990s to 2014, complemented by a review of relevant literature, as well as a series of more than $50 \mathrm{semi}$-structured interviews. Interviews were conducted with relevant stakeholders, from government departments (including the Department of Energy (DoE) and the National Treasury's (NT) Public-Private Partnership Unit), the National Energy Regulator of South Africa (NERSA), financiers, the national utility and IPPs, to academics and consultants. Following these interviews, a workshop was hosted with these stakeholders to discuss findings of the review of the regulation of renewable energy in South Africa. This interactive and iterative research process has contributed to formulating the findings of the paper.

The remainder of the paper proceeds as follows. Section 2 discusses the success of the programme in developing the renewable energy sector and reflects on South Africa's experience in the introduction of renewable energy and IPPs. Sections 3 to 9 draw a series of seven key lessons. Remaining challenges and areas of improvements are also investigated. Section 10 concludes with a discussion on the way forward.

\section{THE SUCCESS STORY OF THE RENEWABLE ENERGY INDEPENDENT POWER PRODUCER PROCUREMENT PROGRAMME}

The South African government has progressively developed a procurement framework to support large-scale renewable energy-based power generation and introduce IPPs in the country's energy market. Several initial attempts failed to effectively procure power from IPPs. Initial programmes, such as the Pilot National Cogeneration Programme, the Medium Term Power Purchase Programme and the Multisite Base-load Independent Power Producer Programme, were conceptualised by Eskom in 2007-2008 with the primary objective of expanding generation capacity. These programmes were however all interrupted due to the lack of readiness from both government and the private sector (DoE, 2009a; Yelland, 2009). Following these programmes, government needed to create a credible procurement programme. NERSA accordingly developed a Renewable Energy Feed-In Tariff (REFIT) mechanism to procure power output from qualifying renewable energy generators at predetermined prices. Faced with political and legal challenges, the REFIT policy was then abandoned in favour of an auction system (Baker, 2012; Creamer, 2011). A lengthy transition process resulted in the DoE, assisted by the NT's Public-Private Partnership Unit, launching the REIPP procurement programme in August 2011.

The first phase of the REIPP procurement programme has been designed with an initial allocation of 3625 megawatt (MW) to be procured from large-scale IPPs over a maximum of five bid windows by 2016, as determined by the Minister of Energy under Section 34(1) of the Electricity Regulation Act No. 4 of 2006. TABLE 1 illustrates the breakdown of energy sources to meet this target and reveals the significant targets set for onshore wind and solar photovoltaic (PV) technologies and the increasing interest in concentrated solar power (CSP), in line with the country's current electricity plan. While no capacity cap (other than the total allocation of the programme) was set in the first round, the allocation for subsequent rounds has been determined based on the initial market response to encourage competition in the renewable 
energy sector. The first three rounds have largely been oversubscribed, a testament of the interest for the programme, and resulted in committed investment of ZAR 150 billion.

TABLE 1: Total megawatt awarded per technology, bid responses and preferred bidders in the REIPP procurement programme

\begin{tabular}{|c|c|c|c|c|c|c|}
\hline Awards (MW) & $\begin{array}{c}\text { Initial } \\
\text { determination } \\
(2012-2016)\end{array}$ & $\begin{array}{c}\text { Second } \\
\text { determination } \\
(2017-2020)\end{array}$ & $\begin{array}{l}\text { Round } 1 \\
\text { allocation }\end{array}$ & $\begin{array}{l}\text { Round } 2 \\
\text { allocation }\end{array}$ & $\begin{array}{l}\text { Round } 3 \\
\text { allocation }\end{array}$ & $\begin{array}{c}\text { Total } \\
\text { allocation }\end{array}$ \\
\hline Wind & 1850 & 1470 & 634 & 563 & 787 & 1984 \\
\hline Solar PV & 1450 & 1075 & 632 & 417 & 450 & 1499 \\
\hline CSP & 200 & 400 & 150 & 50 & 200 & 400 \\
\hline Small hydro & 75 & 60 & 0 & 14.3 & 0 & 14.3 \\
\hline Landfill gas & 25 & 47.5 & 0 & 0 & 18 & 18 \\
\hline Biomass & 12.5 & 47.5 & 0 & 0 & 16.5 & 16.5 \\
\hline Total & 3625 & 3100 & 1416 & 1044.3 & 1456 & 3916 \\
\hline $\begin{array}{l}\text { Bid responses } \\
\text { received }\end{array}$ & N/A & $\mathrm{N} / \mathrm{A}$ & 53 & 79 & 93 & 225 \\
\hline Preferred bidders & $\mathrm{N} / \mathrm{A}$ & $\mathrm{N} / \mathrm{A}$ & 28 & 19 & 17 & 64 \\
\hline Success rate & N/A & $\mathrm{N} / \mathrm{A}$ & $53 \%$ & $24 \%$ & $18 \%$ & $\mathrm{~N} / \mathrm{A}$ \\
\hline
\end{tabular}

Source: TIPS, based on DoE, 2013a and DoE, 2012

In less than two and a half years, 64 projects have been approved, of which 47 have already achieved financial close for a total of $3916 \mathrm{MW}$, i.e. more than the original allocation of 3625 MW. The allocations for onshore wind, solar PV and CSP have been already exceeded for the 2012-2016 period. In December 2012, the DoE published an additional determination of $3100 \mathrm{MW}$ for the 2017-2020 period, of which 307.5 MW were made available for the third bid window, bringing the total determination for large-scale projects to $6725 \mathrm{MW}$ (Dok, 2013b). De facto, a part of the third round as well as upcoming bidding windows for the 2014-2016 period are already carving up the determination for the 2017-2020 period, essentially due to the positive market response and the excellent quality of projects. Practically, all projects selected as preferred bidders have so far reached financial close and the first project, Scatec Solar's 75 MW solar PV plant, was connected to the grid three months ahead of schedule in September 2013 (Clover, 2013). These positive achievements were no accident and have resulted from continual policy and regulatory learnings from previous initiatives as well as the iterations of the current programme.

\section{POLICY SPACE AND POLITICAL SUPPO RT ARE A PREREPUISITE}

From the publication of the 2003 White Paper on the Renewable Energy Policy of the Republic of South Africa (DME, 2003), which set the objective of generating 10000 gigawatt-hour of renewable energy by 2013 (approximately $4 \%$ of the energy mix), to the procurement of the first MW of generation capacity in 2011, a long and complex policy development process took place. 
Only when policy certainty on the role of renewable energy and the associated investment strategy (i.e. the role of the private sector) was achieved could the procurement framework be successfully implemented.

South Africa has been considering the introduction of IPPs, partially for the generation of renewable energy-based electricity, since the 1998 White Paper on Energy Policy (DME, 1998). A blueprint for a competitive electricity supply industry was accordingly produced for Cabinet in May 2001, but was eventually discarded in May 2004. Only the gradual introduction of IPPs resulted from the 2001 blueprint. In 2003 Cabinet approved the participation of the private sector in the electricity industry and resolved that future power generation capacity would be divided between Eskom (70\%) and IPPs (30\%) (Steyn, 2013). In a statement on 5 September 2007, Cabinet designated Eskom as the single buyer of power from public and private producers, mandating the state-owned enterprise to ensure that "adequate generation capacity is made available and that $30 \%$ of the new power generation capacity is derived from IPPs" (GCIS, 2007). Cabinet further specified that over the 2007-2027 period, "Eskom will build all nuclear power plants in South Africa and the IPPs will build more than $50 \%$ of all non-nuclear power plants" (GCIS, 2007).

Large-scale commitment to renewable energy was achieved only in 2011 with the Integrated Resource Plan for Electricity 2010-2030 (IRP 2010). Promulgated in May 2011, the IRP 2010 plans for $17.8 \mathrm{GW}$ of new build renewable energy over the 2010-2030 period, in addition to $1.1 \mathrm{GW}$ of already committed capacity. The plan intends for renewable energy technologies to supply $42 \%$ of the new additional capacity over the $2010-2030$ period or $9 \%$ of the total electrical energy in 2030 (DoE, 2011). These two concomitant policy trends on the role of renewable energy and IPPs have shaped the development of procurement programmes in the country.

The IRP 2010 and the 2011 ministerial determination created a clear policy space for renewable energy in South Africa. This clarity assured investors, through policy and planning, that renewable energy would play a sizeable role in the country's electricity mix. It also opened the door for the design and implementation of an ambitious procurement mechanism, providing further certainty on the demand and procurement of renewable energy.

Benefiting from these positive evolutions, the REFIT programme, in development since 2007, was set to be the national procurement framework for renewable energy. The scheme had largely resolved the flaws that characterised previous initiatives and developers had already prepared to submit their projects to participate in the REFIT policy (Eberhard, 2013). As concerns arose in 2008/2009 around the REFIT policy, the rationale underpinning the shift from a feed-in tariff to an auction programme took prominence, eventually leading to the introduction, with full political support, of the existing competitive bidding process.

Going forward, long-term certainty on the future of the procurement scheme, in terms of megawatt capacity and technology, must be maintained. The publication in November 2013 of an update of the IRP, while advocating that the current renewable energy programme should be continued with additional annual rounds (of $1000 \mathrm{MW}$ capacity for both solar PV and wind, 200 MW for CSP and potentially hydropower at competitive rates), has re-introduced a degree of uncertainty. The update slightly reduces the allocation to renewable energy from $18.8 \mathrm{GW}$ to 17.4 $\mathrm{GW}$. It also suggests a shift from wind to solar energy in the coming years, by cutting the total generation capacity allocated to wind energy in 2030 (from $9.2 \mathrm{GW}$ in the current IRP to $4.4 \mathrm{GW}$ in the 2013 update) and increasing the share of solar PV (from 8.4 GW to $9.8 \mathrm{GW}$ ) and CSP (from 1.2 $\mathrm{GW}$ to $3.3 \mathrm{GW}$ ) (DoE, 2013c). While reviewing and updating the country's electricity plan is a 
necessary ongoing exercise, further certainty on the allocations per technology must be ensured in the process to provide clarity to the sector.

\section{INSTITUTIONAL ARRANGEMENTS ARE AT THE CRUX}

Over and above policy and political support, the design and implementation of successive IPP programmes in South Africa has raised the importance of institutional arrangements. Institutional leadership and political will (to take and implement decisions) are cornerstones of a successful procurement programme; and the active participation of all relevant stakeholders is essential to an effective and efficient design and implementation.

Early programmes driven by Eskom largely failed as a result of inadequate leadership, oversight and political support. Project developers were reluctant to participate owing to Eskom's role as an industry player, i.e. as a generator, transmitter and distributor, as well as administrator and referee, with little oversight to ensure that the utility would not leverage its monopoly in the electricity supply industry. This demonstrated the need for an independent institution. Independent price setting with clear cost-recovery rules not dependent on Eskom's financial standing was also required.

Likewise, NERSA's REFIT programme increasingly faced political and legal challenges, which ultimately resulted in its abandonment to the benefit of a DoE-led scheme. The REFIT policy was conceptualised within NERSA's Electricity Regulatory Division in 2006/2007, following study tours to Germany and Denmark. Despite some opposition within NERSA itself as well as reluctance from the then Department of Minerals and Energy (DME) and Eskom, the development of a REFIT policy gained traction at NERSA's board level in June 2007 (Baker, 2012). However, the DoE, supported by the NT, later identified that by developing the REFIT, NERSA was acting beyond its mandate stipulated in the Electricity Regulation Act No. 4 of 2006. According to the Act, the function of developing energy policy belongs to the DoE, while NERSA acts as an implementer. While NERSA understood at the time that such a programme was meant to be developed by the DoE, the regulator explains that, owing to administrative issues that caused delays, NERSA ended up initiating the process all within the legislative framework in place at the time.

In addition, the NT and the DoE were convinced that NERSA had neither the budget nor the expertise to efficiently run a REFIT, and that the relatively high prices set by NERSA meant that the programme was not financial feasible. The risk of a large oversubscription, notably in relation to Eskom's financial and grid connection capacity (Baker, 2012), was particularly concerning (Yelland, 2009).

In January 2009, the then-DME put forward the proposal of a bidding system, also shifting the strategic and planning responsibilities from NERSA to Eskom, and giving the Minister of Energy wide discretion regarding NERSA's REFIT process (IDASA, 2010). In August 2009, the DoE's Electricity Regulations on New Generation Capacity, which enacted this shift, were approved (DoE, 2009b). This followed the Dok receiving legal advice that feed-in tariffs could be challenged against South Africa's public finance and procurement laws. Evidence suggests that a REFIT would have been inconsistent with the Public Finance Management Act No. 1 of 1999 (as amended) due to the absence of price competition. The 'first come first serve' basis upon which bids would have essentially been chosen under the REFIT was considered not to be in line with the procurement regulation that stresses competitive bidding (Creamer, 2011). An auction system was considered as doing more to encourage price competitiveness among developers than the 
feed-in tariff. This analysis can however be challenged: although price would not have been a differentiating factor, competition would have occurred based on other criteria, most likely local economic development.

In November 2010, revised New Generation Regulations published by the DoE, supported by the NT, effectively removed NERSA and Eskom's functions to implement a REFIT, and replaced the scheme with a competitive bidding process under the governance of the DoE and the NT (DoE, 2009b). The feed-in tariff was effectively never implemented and not a single MW of power was signed under the REFIT programme. Ultimately, the political play between NERSA and the Dor appeared to become a dispute over turf, and the change in regulation was more a political matter than a technical problem. What is certain in the shift from the REFIT to the REIPP procurement programme is that NERSA's role has been significantly diminished. While facilitating the entry of IPPs into the electricity generation market and, importantly, ushering in renewable energy in the energy supply mix, the shift to a Do\&-led bidding process served to reinforce direct governmental control over the development of renewable energy in the country.

The political will and leadership emanating from the Dor and the NT that drove the establishment of the programme have been instrumental to its success. The two institutions are central in drafting the Request for Proposals and the methodology for project selection. The Dok, as driver and coordinator of the programme, has provided policy clarity and direction for renewable energy development. This is complemented by the financial and technical support of the NT. In addition, all relevant stakeholders are actively involved in the design and implementation of the scheme, as illustrated in FIGURE 1, in comparison to previous initiatives, which relied heavily on one single institution. Other government departments provide advisory inputs as per their areas of expertise. Whereas Eskom and NERSA were the architects of previous independent power procurement programmes and remain instrumental to the success of the programme, they both now have secondary decision-making functions in the process. The regulator was largely responsible for designing and administering the REFIT. Under the REIPP procurement programme, NERSA is tasked with awarding generation and distribution licences to successful IPPs for the period and MW capacity in line with the power purchase agreement (PPA), with less autonomous decision-making power about the role of renewable energy. This is indeed more an instruction that the regulator carries out as stipulated by the Request for Proposals than an independent decision. Eskom's System Operator is responsible for designing and ensuring that the grid infrastructure can equitably accommodate renewable energy projects to feed into the national grid. The utility's Grid Access Unit provides technical analysis on the connection of projects to the grid and supplies IPPs with cost-estimate letters and budget quotes on these options. Last but not least, project developers and the community of financiers, in addition to developing and financing renewable energy projects, are dynamically considered in the continual improvement of the scheme, through consultations with the NT and the Dor.

Owing to the complex and interconnected nature of institutional arrangements associated with the REIPP procurement programme, areas of improvements still exist. Issues around the grid connection and associated processes, which create uncertainty for IPPs, should be mitigated. IPPs rely on Eskom to obtain a cost-estimate letter and budget quotes in a timely fashion for their grid connection. Uncertainty around the timeline for grid connection and the lack of accuracy of the cost-estimate letter and budget quotes provided by the utility, which are accurate at $+/-40 \%$ and $+/-15 \%$ respectively, have raised some financial risk for IPPs. 


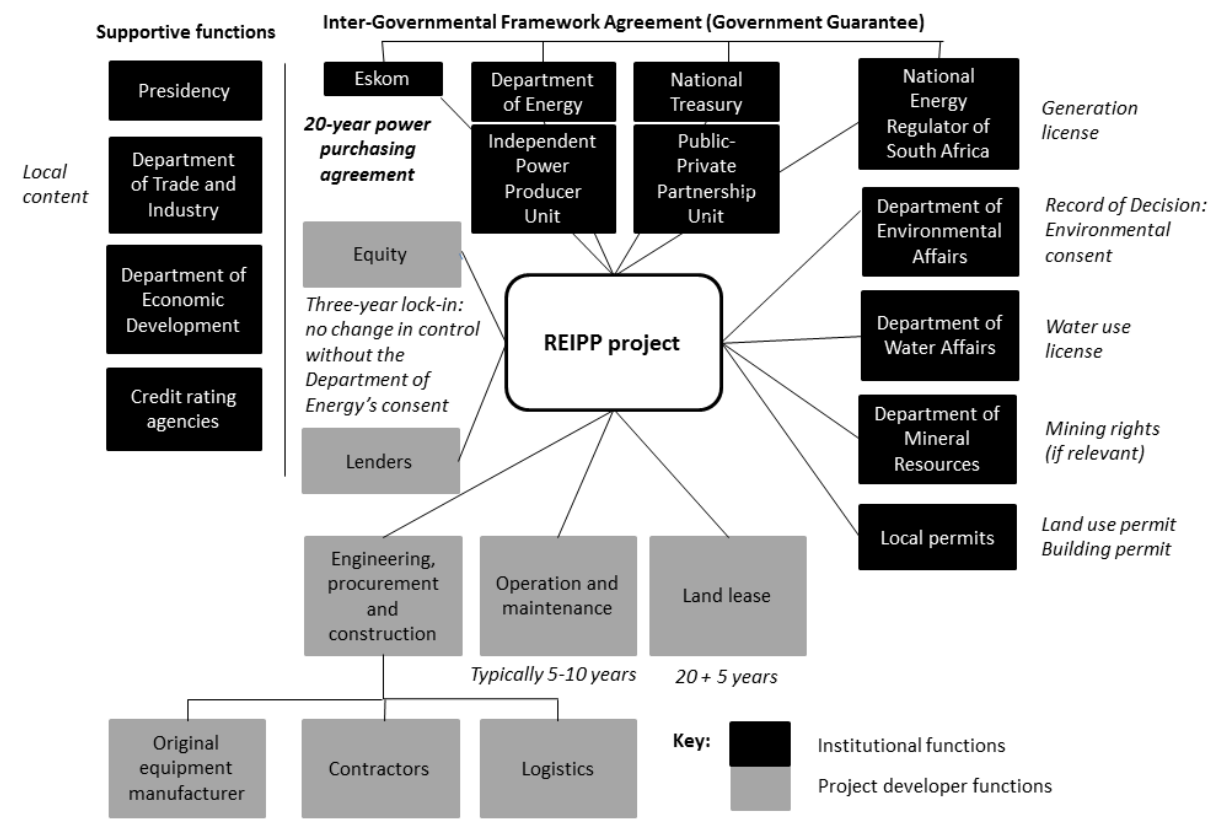

FIGURE 1: Institutional arrangements around the REIPP procurement programme

Source: TIPS, based on Pickering (2013); Haffejee (2013)

Ultimately, more certainty is required at the time of submission to enable efficient planning and ensure the lowest possible prices and maximum economic development benefits. Another area of amelioration is the misalignment of multiple authorisations required from national, provincial and local levels and the associated application processes, which should be streamlined and fast-tracked, particularly in the case of water licences, to facilitate project development. While ameliorations could be achieved on the coordination of all involved institutions, the success of the REIPP procurement programme lies in the inclusion of all stakeholders from government departments, to the regulator and the state-owned utility, to the private sector. Had just one of these vital players been missing from the programme design and consultation, the scheme would undoubtedly have not been such an overwhelming success.

\section{MARKET READINESS UNDERLINES THE POSITIVE RESPONSE OF THE PRIVATE SECTOR}

The readiness of the domestic market, progressively built over a number of years, has played a critical role in the positive response to the REIPP procurement programme. As such, the existing programme has benefited from previous initiatives and schemes, which contributed to preparing both domestic and international private developers for their entry into the electricity market in South Africa.

Despite failing to take off, early programmes developed by Eskom prepared and tested the market. They created expectations and constituted building blocks of the current achievements (DoE, 2009a; Yelland, 2009). Similarly, the REFIT programme, which had largely resolved the 
flaws that characterised previous endeavours, was instrumental to the enthusiastic market response experienced in the REIPP procurement programme. As such, preferred bidders from the first round of the REIPP procurement programme were predominantly developers who prepared to submit projects under the REFIT programme (Eberhard, 2013).

The unexpected change in the procurement framework nevertheless raised concerns over whether there would be further changes, without notice or consultation going forward, i.e. would this remain government's modus operandi to deal with IPPs? This became an important consideration in the design of REIPP procurement programme, which institutionalises continual engagement with the private sector. In addition, the Do\& provides valuable feedback on the evaluation of unsuccessful bids, allowing project developers to improve the quality of their bids and often resubmit unsuccessful projects in subsequent windows.

Furthermore, the design of the REIPP procurement programme was tailored by the DoE and the NT to the South African context, against the initial prescriptions of international advisors. The scheme was conceived as a rolling programme, and not a once-off exercise, which contributed to creating market certainty, confirmed the readiness of the private sector and encouraged the participation of developers. Adequate intervals between bidding rounds have allowed the Dok the flexibility to respond to design challenges (in order to maximise benefits for the country) as well as issues raised by the private sector. This resulted in growing interest from the private sector, attested to by the increasing number of bids received, from 53 proposals in the first round to 79 and 93 in the second and third rounds respectively (DoE, 2013a). The maximum size for a single project was also adjusted (at $75 \mathrm{MW}$ for solar PV and $100 \mathrm{MW}$ for CSP for example) to match local requirements and characteristics. Well-structured, timely and tailor-made implementation, to match and further build market readiness, has been vital to establish confidence and certainty in the market and prepare all players. Linking the programme design, i.e. demand, with the market response, i.e. supply, has constituted a keystone of the significant interest from the private sector and ultimately the success of the REIPP procurement programme.

\section{FAIR, TRANSPARENT, AND CONSISTENT EVALUATION CRITERIA PROVIDE EFFECTIVE GUIDELINES FOR THE MARKET}

With regards to the actual implementation of a procurement programme, the publication of transparent, consistent and independently reviewed evaluation criteria has emerged as a critical condition for the private sector. The current evaluation framework, building on the experience of the REFIT policy, ensures a fair and level playing field for all participants. Overall, financiers have commended the programme for the extensive due diligence required of developers in their bids, as well as its clarity and reliability.

The evaluation process of the REIPP procurement programme is composed of two clear-cut phases. In a first pre-qualification stage, bidders must meet a set of minimum criteria. Bidders have to first satisfy certain minimum threshold requirements in six areas: financial; technical; commercial and legal; land; economic development; and environment. They must inter alia demonstrate the readiness of the project (land acquisition, funding, technologies, suppliers, ability to meet deadlines, environmental consent, etc.), its financial viability and the arrangements to meet minimum requirements in terms of economic development. As a rule, and in order to secure local participation, the project company must also comprise $40 \%$ ownership 
participation by a South African entity. Bids meeting all these initial requirements are admitted to the second stage of the auction, where they are assessed on a competitive basis.

TABLE 2: Local content requirements across the first three rounds of the REIPP procurement programme

\begin{tabular}{|c|c|c|c|c|c|c|}
\hline \multirow{2}{*}{$\begin{array}{l}\begin{array}{c}\text { Bidding rounds/ } \\
\text { Technology }\end{array} \\
\text { Criteria }\end{array}$} & \multicolumn{2}{|c|}{ Bidding round 1} & \multicolumn{2}{|c|}{ Bidding Round 2} & \multicolumn{2}{|c|}{ Bidding Round 3} \\
\hline & Threshold & Target & Threshold & Target & Threshold & Target \\
\hline Onshore wind & $25 \%$ & $45 \%$ & $25 \%$ & $60 \%$ & $40 \%$ & $65 \%$ \\
\hline Solar PV & $35 \%$ & $50 \%$ & $35 \%$ & $60 \%$ & $45 \%$ & $65 \%$ \\
\hline $\begin{array}{l}\text { CSP without } \\
\text { storage }\end{array}$ & $35 \%$ & $50 \%$ & $35 \%$ & $60 \%$ & $45 \%$ & $65 \%$ \\
\hline CSP with storage & $25 \%$ & $45 \%$ & $25 \%$ & $60 \%$ & $40 \%$ & $65 \%$ \\
\hline Biomass & $25 \%$ & $45 \%$ & $25 \%$ & $60 \%$ & $40 \%$ & $65 \%$ \\
\hline Biogas & $25 \%$ & $45 \%$ & $25 \%$ & $60 \%$ & $40 \%$ & $65 \%$ \\
\hline Landfill gas & $25 \%$ & $45 \%$ & $25 \%$ & $60 \%$ & $40 \%$ & $65 \%$ \\
\hline Small hydro & $25 \%$ & $45 \%$ & $25 \%$ & $60 \%$ & $40 \%$ & $65 \%$ \\
\hline
\end{tabular}

Source: TIPS, based on Campbell, 2012

In the second stage of the evaluation process, bids are reviewed based on weighted criteria, namely $70 \%$ for their price offer and $30 \%$ for their additional contribution to economic development (i.e. over and above minimum requirements). Within the 30 points (out of 100) which are awarded for economic development, different components are weighted as follows: job creation (25\%), local content (25\%), ownership (15\%), management control (5\%), preferential procurement (10\%), enterprise development (5\%), and socio-economic development (15\%) (DoE, 2013b). For each category, points are allocated based on minimum desired targets, over and above minimum thresholds. In a given category, only meeting the minimum threshold translates into zero points, while reaching the target grants the maximum number of points. From the threshold to target, a linear relationship determines the total of points awarded to the bid. TABLE 2 illustrates these thresholds and targets for local content across the first three bidding windows. This system is meant to ensure minimum economic development contributions from project developers while encouraging them to aim for higher targets.

The evaluation mechanism has contributed to creating certainty and ensuring the large participation and the selection of the most competitive bids. The rigour required to meet evaluation criteria and each step in the bidding process, while welcomed by the private sector, has nevertheless proven to be extremely time-consuming and expensive. Key advisors, such as legal experts, are particularly costly for project developers, and can represent up to $15 \%$ of project development costs. The need to reduce the cost of meeting all requirements has arisen for IPPs. As such, the design of evaluation criteria, particularly their stringency, is reviewed between every bidding window, factoring market dynamics and local capabilities, notably in terms of local content requirements. 


\section{FINANCING HINGES ON A BANKABLE POWER PURCHASE AGREEMENT}

Not only did the market require clear guidelines for IPPs, but banks needed the assurance that deals could be structured around reasonable and sensible terms and aligned to their investment mandates. The PPA, which is the only source of revenue for developers and for commercial banks financing IPPs, is the cornerstone of the success of any IPP programme. Most notably, the PPA is used to divide and allocate risk between all parties involved. A multitude of risks can be associated with the construction and profitable operation of a renewable energy-based power plant, from foreign exchange, environmental assessments and authorisations, the connection to the transmission and distribution networks, revenue collection, to timely and on-budget plant construction and plant operation. From the point of view of IPPs, and financial institutions backing their projects, the only acceptable risks that project developers can shoulder are linked to building and operating the power plant. All other risks must be mitigated by the state, between the utility, the NT and the Dor.

Appropriate risk allocation was a problem in early procurement schemes as well as the REFIT programme. NERSA's (2009a) initial draft of a PPA in July 2009 was criticised by developers and investors for allocating too much risk to IPPs (Baker, 2012). Developers identified that there was no stabilisation clause for law changes, which posed a realistic risk, as demonstrated in previous procurement programmes which were abandoned without compensation to IPPs (Brodsky, 2010). The PPA did not adequately delimit the buyer of renewable energy. Given government's clear intention to introduce an Independent Systems and Market Operator (ISMO), this did not guard against the consequences of a restructuring of the electricity supply industry. Neither was the Renewable Energy Purchasing Agency (REPA) clearly defined. Consequently, no PPA was signed with Eskom at that stage, as developers and banks insisted on a PPA that would be underwritten by government.

The inability of different stakeholders to agree on how to apportion risk was a key reason for the halt in signing PPAs. The NT was sceptical about providing a PPA that would be underwritten by government, as this would threaten the country's balance sheet. At the same time, the NT recognised that developers were unwilling to enter into a PPA underwritten by Eskom alone (Baker, 2012; Eberhard, 2013).

Under the REIPP procurement programme, the PPA is held for a period of 20 years and in local currency. It allocates risk between the parties based on investment-friendly terms. It guarantees payment of an agreed tariff for power generated on a take-or-pay basis (Stemple, 2013). Essentially, this means that irrespective of power demand by the grid, if the power is generated, the tariff will be paid by Eskom for each kilowatt of energy produced. The tariff is agreed upon the award of the preferred bid status and is indexed to the rate of inflation over the duration of the contract with Eskom.

On the one hand, answering the unwillingness from developers to enter into PPAs underwritten by Eskom, the agreement underwritten by the NT should Eskom default on the terms of the agreement. This includes if Eskom fails to connect renewable energy projects to the grid and if the utility fails to pay for the generated electricity. Under this PPA, Eskom is accountable to the NT and has a vested interest to ensure grid connection. The DoE has also separately contracted with the project companies in order to offer recourse for project investors in the event that Eskom fails to meet its obligations under the PPA. Under a Direct Agreement between the Do\& and the lenders of the project, the DoE, underwritten by the NT, commits to taking on payments due to the project company should Eskom default on payments. This governmental backstop has 
earned the REIPP procurement programme significant credibility with international investors (Stemple, 2013).

On the other hand, should the project company fail to generate the contracted energy, the lenders are asked to step in and find a replacement project company, if feasible. If not, the allocation for that project could be put up for bid in subsequent rounds. In the case of IPPs defaulting on supplying the agreed amount of electricity due to weather instability or plant degradation or destruction, the liability falls on the IPP and its financiers. In this case, commercial lenders include comprehensive insurance to cover the loss and protect the developer, as part of the project finance. Should there be an inability to generate electricity caused by a fault in the construction of the plant, the liability falls on the contractor as agreed in the Engineering, Procurement and Construction ( $E P C)$ contract, the predominant form of construction contract used on large-scale infrastructure projects. Should there be a dispute between IPPs and Eskom over terms not being met in the PPA, the responsibility of mediating the conflict falls squarely on NERSA.

In relation to risk allocation and financing, some modifications are recommended to improve the financial close phase. The financial close process should be revised to prevent delays by matching the signing of the PPA and the Implementation Agreement (between the Dor and the project company) with the date of financial close. While the South African government carries the foreign exchange risk between the bid submission and the signature of the PPA and the Implementation Agreement (allowing IPPs to adjust their price offering for any evolution of the exchange rate in between the two dates), project developers are exposed from the signature to the date of financial close (around one month). The financial close process should also better integrate EPC contractors as initial contractual terms are substantially renegotiated after the award of the preferred bidder status to ensure the best and most competitive offer.

The significance of the PPA is regarded as a crucial factor in the success of the REIPP procurement programme by commercial banks and IPPs. Notably, the allocation of risk between all stakeholders has contributed to a bankable PPA and the success of the programme in attracting significant interest from developers in the sector.

\section{GETTING THE PRICE RIGHT IS AS IMPORTANT AS LEARNING HOW TO GET IT RIGHT}

A critical factor in establishing a viable programme for renewable energy is the price of the procured electricity. From a government perspective, getting the price right remains one of most challenging tasks. While a feed-in tariff or auction system can be used, the mechanisms of the two systems are inversed and will tend to bring different benefits, particularly in the short term. They differ mostly in terms of pricing approach and procurement decision-making. Whereas a feed-in tariff is based on setting a price per kilowatt-hour for a certain renewable energy technology, competitive bidding relies on capacity allocation, price caps and procurement criteria. In other words, a feed in tariff is based on a fixed price and a varying quantity, while a bidding system is structured around a set quantity and a variable price. On the one hand, the main advantage of an auction system is its ability to drive pricing down through competition. A feed-in tariff, by predetermining prices, exposes government to the risk of getting prices wrong (offering high returns to investors in the case where tariffs are set too high or preventing the development of the sector if tariffs are set too low). On the other hand, with price being the 
largest determinant in the evaluation of bids in the auction system, bids are less competitive in terms of economic development (even though minimum economic development criteria are set). Developers tend to meet minimum requirements in terms of local content, favouring the price component of their bid. In a system based on a feed-in tariff, the price is pre-determined and fixed. Provided that the REFIT scheme is not run on a 'first come first serve' basis, developers will tend to compete on other aspects of their projects, such as local content, industrial development, job creation and social development outcomes, to increase their chance of success, and potentially resulting in higher economic development benefits than in the auction system. The logics underlying an auction system and a feed-in tariff are inversed and will tend to bring different benefits, particularly in the short term.

In December 2008, NERSA proposed a set of tariffs regarded as close to international standards. Stakeholders stressed that tariffs were too low to make any renewable energy project viable and called for NERSA to review them in order to create a viable renewable energy market (Baker, 2012). These tariffs and their successive revisions in 2009 and 2011 are presented in TABLE 3. In March 2009, NERSA released revised tariffs fully indexed on inflation designed to cover generation costs plus a real return on equity of $17 \%$ (NERSA, 2009b). Unlike the original tariffs, these were generally regarded as generous by developers (Eberhard, 2013). The private sector, through an informal advisory committee notably composed of leading South African banks, played an influential role in their calculation. The March 2009 tariffs were calculated on the assumption of a high interest rate and a high dollar exchange rate, and input from developers who were hoping for a higher return. NERSA stated that the 2009 tariffs were set at these higher than international levels not only to ensure a return on investment for developers, but also to incentivise a small renewable energy market and the long-term commercial viability of the sector (NERSA, 2009c). Nevertheless, developers expressed apprehension around the financial capacity of the South African government to sustain tariffs at these levels over the 20 -year lifetime of the PPA (Eberhard, 2013; NERSA, 2011). Such high tariffs would create excessive profits for IPPs and make electricity less affordable for consumers. In turn, this could impede innovation among developers for more cost-cutting, efficient and better quality technologies and result in inefficient operations (Eberhard, 2013).

In March 2011, NERSA unexpectedly released lower feed-in tariffs, arguing that a number of parameters used in 2009, such as exchange rates and the cost of debt, had changed (NERSA, 2011). The new tariffs were in line with international trends in the cost of renewable energy technologies, which had decreased since 2009. There was speculation that the cut may have also been an attempt to trade lower prices for a larger allocation of renewable energy to be included in the IRP 2010. The lower tariffs did not raise concerns among developers, who were reassured by the larger allocation of independent generation capacity (Eberhard, 2013). The March 2011 tariff revisions also signalled a shift in the tariff structure. Notably, the capital component of the tariffs would no longer be fully indexed on inflation. However, NERSA maintained the required real return for equity investors of $17 \%$ in its final revision (NERSA, 2011). The successive changes operated by NERSA and the mixed reactions that these triggered illustrate the difficulty of the exercise. As the regulator and the private sector appeared to come to an agreement on feed-in tariffs, the shift to an auction system and the involvement of the DoE and NT changed the procurement design and implementation.

With the transition from a feed-in tariff to an auction system, a pricing mechanism was no longer required. Tariff caps, determined by the Dok, were however used to limit the risk of high prices linked to inter alia a lack of competitive behaviour, particularly for the first bidding 
window. While the 2009 REFIT tariffs were initially thought to constitute the upper limit, new price ceilings were published, as summarised in TABLE 3.

TABLE 3: REFIT tariffs (2008-2011) and REIPP price caps (in ZAR/kWh)

\begin{tabular}{lccccccc}
\hline Technology & $\begin{array}{c}\text { December } \\
2008\end{array}$ & $\begin{array}{c}\text { March } \\
2009\end{array}$ & $\begin{array}{c}\text { March } \\
2011\end{array}$ & $\begin{array}{c}\text { REIPP round 1 } \\
\text { price cap }\end{array}$ & Round 1 & Round 2 & Round 3 \\
\hline Wind & 0.66 & 1.25 & 0.94 & 1.15 & 1.14 & 0.89 & 0.66 \\
CSP & 0.61 & 2.10 & 1.84 & 2.85 & 2.68 & 2.51 & 1.46 \\
Solar PV & -- & 3.94 & 2.31 & 2.85 & 2.75 & 1.65 & 0.88 \\
Small hydro & 0.74 & 0.94 & 0.67 & 1.03 & -- & 1.03 & -- \\
Landfill gas & 0.43 & 0.90 & 0.54 & 0.84 & -- & -- & 0.84 \\
Biomass & -- & -- & -- & 1.07 & -- & -- & 1.24 \\
\hline
\end{tabular}

Source: TIPS, based on DoE, 2013a; Greyling, 2012; NERSA, 2011

New developers were not yet ready to put forward competitive bids in the first window, which was utilised in many ways as a round of observation. In addition, no capacity cap (other than the total allocation of the programme) was set in the first round, resulting in a lack of competition and failing to create pressure on the bidders to reduce their price offering. As a result, prices in the first round were very close to the prescribed ceilings. In addition, price caps set too low played a part in the absence of successful projects in the first two rounds for some technologies, such as landfill gas and biomass.

In order to stimulate competition and drive prices down, the maximum generation capacity was capped in the second and third bidding windows and the price ceilings per technology were adjusted (downward in the case of solar PV, CSP and wind). Tariffs have dropped significantly over the three rounds. For example, prices plummeted on average from ZAR 2.75/kWh to $88 \mathrm{c} / \mathrm{kWh}$ for solar PV, and from ZAR $1.14 / \mathrm{kWh}$ to $66 \mathrm{c} / \mathrm{kWh}$ for wind. This trend essentially resulted from project developers being more experienced and familiar with the programme, an increased maturity of technologies, aggressive (price) competition, reduced price ceiling for some technologies and the allocation of a capacity limit for each technology from the second round onwards. As a result, prices received for the second and third auction rounds were very competitive and even lower than expected (IRENA, 2013b). This success story, resulting from a well-crafted combination of price caps, maximum project size and determined allocation, has been one of the major achievements of the REIPP procurement programme. It might however have occurred as the expense of other policy objectives associated with the government-run scheme.

\section{MAXIMISING LOCAL ECONOMIC DEVELOPMENT CENTRES ON UNDERSTANDING THE MULTIPLE OBJECTIVES OF RENEWABLE ENERGY PROCUREMENT}

Developing the renewable energy sector in South Africa has aimed to achieve several objectives, from the procurement of additional generation capacity and affordable electricity, to 
introducing IPPs to the market, to contributing to green economy and broader economic development goals. While some priorities of the current procurement programme fit perfectly with the overall energy system and the country's policy framework, such as commissioning new generation capacity and contributing to climate change mitigation policies, others appear more conflictual.

The REIPP procurement programme aims to procure affordable renewable energy-based electricity from IPPs. As a nascent industry in South Africa, renewable energy has in the short term required some governmental support, in the form of a price premium. The sustainability of the programme also relies on Eskom's ability to incorporate IPPs into the electricity grid and procure the contracted power from preferred bidders. This has resulted in budgetary implications for the national utility, which have been passed on to consumers through tariff increases. In the medium to long term, the REIPP procurement programme will however effectively contribute to generating affordable electricity, as the levelised cost of renewables technologies decreases. Government also aims to stimulate employment generation and develop an industrial base for the local manufacturing of the inputs required in renewable energy projects. Social development outcomes, primarily through community ownership, have also been included as part of the objectives of the programme. Economic development objectives have focused on ensuring that South Africans participate, own and benefit from renewable energy activities in the country. The structure of the programme has been explicit in facilitating this, although economic development criteria remain secondary to price. In the current auction scheme, the emphasis is put on the price offering (accounting for $70 \%$ of the selection process), while developmental outcomes are a smaller part of the weighted criteria (30\%). Traditionally, government's procurement has been based on $80-90 \%$ price consideration (and $10-20 \%$ for developmental objectives such as black economic empowerment). While project developers have committed to job creation, as illustrated in TABLE 4, employment opportunities in the construction and operation of renewable energy-based power plants remain limited. Trade unions have moreover raised concerns about the quality and precarious nature of the jobs generated by the projects, most employment created in the communities surrounding projects being low-skilled security guards.

TABLE 4: Committed job creation for selected technologies over the first three bidding rounds of the REIPP procurement programme

\begin{tabular}{lccc}
\hline Technologies and jobs categories & Round 1 & Round 2 & Round 3 \\
\hline Solar PV jobs in 12 person-months & 8498 & 6079 & 9632 \\
Solar PV jobs per MW capacity & 13.4 & 14.6 & 21.4 \\
Onshore Wind jobs in 12 person-months & 4271 & 4025 & 11118 \\
Onshore Wind jobs per MW capacity & 6.7 & 7.1 & 14.1 \\
CSP jobs in 12 person-months & 3265 & 2344 & 4812 \\
CSP PV jobs per MW capacity & 21.8 & 46.9 & 24.1 \\
\hline
\end{tabular}

Source: TIPS, based on DoE, $2013 a$

In addition, local content requirements, which are leveraged to stimulate employment and develop domestic capacity, involve short-term trade-offs. As the localisation of green 
technologies raises the costs of goods, local content requirements can hinder the shift to sustainable development if they are not in line with the country's capacity and capability, and impede the decrease in prices.

TABLE 5: Trend in local content for selected technologies over the first three rounds of the REIPP procurement programme

\begin{tabular}{lccc}
\hline Technology & Round 1 & Round 2 & Round 3 \\
\hline Solar PV & $29 \%$ & $48 \%$ & $54 \%$ \\
Onshore wind & $22 \%$ & $37 \%$ & $47 \%$ \\
CSP & $21 \%$ & $37 \%$ & $44 \%$ \\
\hline
\end{tabular}

Source: TIPS, based on DoE, $2013 a$

Targets and accordingly the local content share of projects have increased over each bid window to encourage further industrialisation and job creation, as illustrated in TABLE 5. However, the industrialisation envisioned as part of the programme remains constrained owing to the limited megawatt capacity allocated per technology (to create sufficient aggregate demand for international companies to set up manufacturing sites in the country) and the small existing manufacturing base.

In the end, the programme could strengthen its impact on economic development, particularly in terms of local manufacturing and community development, by establishing strong monitoring and evaluation frameworks and further capacitating project developers in meeting economic development requirements. Setting the appropriate instruments to create aggregate demand (required for the development of local manufacturing) could further contribute to enabling the type of economic development and skilled employment envisioned for this programme. In other words, sufficient domestic demand per manufactured good must be ensured. This could take the form of an embedded auction scheme, in which manufacturers would first bid for the provision of certain parts and components (to a share or the entirety of the programme) and developers would then be mandated to use successful manufacturers in the design of their projects in order to be eligible to the programme. In the short term, however, this is likely to come at the expense of other policy objectives attached to the programme, such as cost affordability and the transition to a green economy, and trade-offs between various objectives must be carefully considered in order to maximise benefits to the country.

\section{CONCLUSION: TAKING THE LESSONS FORWARD}

The development of the REIPP procurement programme has a positive illustration of successful policy and regulatory learning processes. The design and implementation of the programme have incorporated the accumulated experience and lessons from previous procurement initiatives as well as the first phases of the existing scheme. The seven key lessons taken from the development and implementation of successive procurement programmes highlight how challenges have been overcome over time. This hinges on the political will and participation of key players as well as the intentional modification of the programme. Moreover, the South African government is continuously working to further improve the mechanism and remove the remaining issues and bottlenecks. As the programme progresses and expands, continual 
improvements, to answer arising challenges, will be required to ensure the sustainability of the programme and the sector as a whole.

The programme has constituted a very efficient springboard for the renewable energy industry in the country by stimulating interest and investment, and laying the foundations for further developments. In addition to procuring large-scale renewable energy-based electricity at increasingly competitive prices, the programme has brought some added benefits to the country in the form of job creation, industrial development, community development and local ownership. Ultimately, the success of the REIPP procurement programme has enabled significant changes in the electricity supply industry by facilitating the entry of IPPs into the generation market and the development of renewable energy in the country. The programme represents a cornerstone feature of the creation of a more competitive and efficient electricity supply industry and the transition to a clean and low-carbon energy mix in South Africa.

Going forward, the development of the renewable energy industry outside government-led programmes should also be considered. The current electricity industry in South Africa and the REIPP procurement programme are structured around Eskom as the single buyer of electricity (as per the single-buyer model prevailing in the country). The Independent Systems and Market Operator Bill, which is meant to create a state entity independent of electricity generators and distributors, and serve as a buyer of electricity from generators and seller of power to customers at wholesale level, remained stalled in Parliament as of September 2014. While remaining fully owned by government, an ISMO would contribute to levelling the playing field by eliminating the potential bias created by the current structure in which the DoE procures energy and trading occurs within Eskom (Unlimited Energy, 2013). It would also open the door for customers to choose their suppliers, i.e. Eskom or an IPP, potentially contributing to sustainable development by renewable energy producers being given preference (Abrahams et al., 2013).

The development and success of the REIPP procurement programme carries important findings for other infrastructure programmes in the country. The private sector and government clusters working in infrastructure development have expressed interest in using the model of the REIPP procurement programme to procure other type of infrastructure projects beyond the energy sector (Munshi, 2013). The NT's task team responsible for the private sector financing of infrastructure, which includes personnel from the Department of Public Enterprises, the Presidential Infrastructure Co-ordinating Commission, business and labour unions, have particularly investigated this possibility. This may trigger a significant shift in how the South African government approaches public-private partnerships and open for the door for more efficient, sustainable, job-creating infrastructure procurement in the country.

\section{Acknowledgement}

This article draws on research undertaken as part of the Regulatory Entities Capacity Building Project, with funding from the South African government's Economic Development Department.

\section{LIST OF REFERENCES}

Abrahams, Y., Fischer, R., Martin, B. \& McDaid, L. (2013). Smart Electricity Planning: Fast-Tracking Our Transition to Smart Electricity Supply for All. Electricity Governance Initiative of South Africa. 
Baker, L. (2012). Power Shifts? The Political Economy of Socio-Technical Transitions in South Africa's Electricity Sector. School of International Development at the University of East Anglia, Norwich.

Bjork, I., Connors, C., Welch, T., Shaw, D., Hewitt, W. \& Mwenechanya, J. (2014). Encouraging Renewable Energy Development: A Handbook for International Energy Regulators. Washington, D.C.: United States Agency for International Development and National Association of Regulatory Utility Commissioners.

Brodsky, S. (2010). South Africa's REFIT Programme - Latest Developments and the Way Forward: Presentation to SENEA.

Clover, I. (2013). Scatec Solar Connects South Africa's First Renewable Independent Power Project to the Grid. [Online] Available: http://www.pv-magazine.com/news/details/beitrag/scatec-solarconnects-south-africas-first-renewable-independent-power-project-to-thegrid_100012682/\#axzz2vfQwZchi. (Accessed 11 March 2014)

Creamer, T. (2011). Fresh Concern that SA Will Abandon REFIT in Favour of Competitive Bids [Online] Available: http://www.engineeringnews.co.za/article/fresh-concern-that-sa-is-poised-toabandon-refit-in-favour-of-competitive-bidding-2011-06-23. (Accessed 30 January 2014).

Department of Minerals and Energy (DME). (1998). White Paper on the Energy Policy of the Republic of South Africa. Pretoria: Department of Minerals and Energy.

Department of Minerals and Energy (DME). (2003). White Paper on the Renewable Energy Policy of the Republic of South Africa. Pretoria: Department of Minerals and Energy.

Department of Energy (DoE). (2009a). Creating an Enabling Environment for Distributed Power Generation in the South African Electricity Supply Industry. Pretoria: Department of Energy.

Department of Energy (DoE). (2009b). Electricity Regulation Act: Electricity Regulations on New Generation Capacity. Government Gazette.

Department of Energy (DoE). (2011). Integrated Resource Plan for Electricity 2010-2030. Pretoria: Department of Energy.

Department of Energy (DoE). (2012). IPP Procurement Programme 2012. Determination under section 34(1) of the Electricity Regulation Act 4 of 2006. Government Gazette.

Department of Energy (DoE). (2013a). Renewable Energy IPP Procurement Programme: Bid Window 3 Preferred Bidders'Announcement.

Department of Energy (DoE). (2013b). Background Information on the REIPP Programme and the RFP. Department of Energy (Dor) (2013c). Integrated Resource Plan for Electricity (IRP) 2010-2030. Update Report 2013. Pretoria: Department of Energy

Eberhard, A. (2013). Feed-In Tariffs or Auctions? Procuring Renewable Energy Supply in South Africa Viewpoint (No. 338), World Bank, Washington, D.C.

Eberhard, A., Kolker, J. \& Leigland, J. (2014). South Africa's Renewable Energy IPP Procurement Program: Success Factors and Lessons. Washington, D.C.: Public-Private Infrastructure Advisory Facility. 
Economic Development Department (EDD). (2010). The New Growth Path: The Framework. Pretoria: Economic Development Department.

Government Communication and Information System (GCIS). (2007). Statement on Cabinet meeting of 5 September 2007. Government Communication and Information System.

Greyling, A. (2012). Renewable Energy Independent Power Producer (REIPP) Procurement Programme - An Eskom perspective.

Haffejee, Y. (2013). Renewable Energy IPP Programme (Presentation for the IRENA Renewable Energy Policies). Eskom, Abu Dhabi.

Institute for Democracy in Africa (IDASA). (2010). Electricity Governance Initiative of South Africa: The Governance of Power, Shedding a Light on the Electricity Sector in South Africa. Pretoria: Institute for Democracy in Africa.

International Renewable Energy Agency (IRENA). (2013a). Renewable Power Generation Costs in 2012: An Overview. Abu Dhabi: International Renewable Energy Agency.

International Renewable Energy Agency (IRENA). (2013b). Renewable Energy Auctions in Developing Countries. Abu Dhabi: International Renewable Energy Agency.

Lafferty, W.M. Ed. (2004). Introduction: Form and Function in Governance for Sustainable Development. In Governance for Sustainable Development: The Challenge of Adapting Form to Function. Cheltenham: Edward Elgar.

Munshi, R. (2013). Vital Lessons for Infrastructure Projects', Business Day Newspaper,. [Online] Available: http://www.bdlive.co.za/indepth/renewable_energy/2013/11/13/vital-lessons-forinfrastructors-projects (Accessed 20 November 2013)

National Energy Regulator of South Africa (NERSA). (2009a). South Africa Renewable Energy Feed-In Tariff (REFIT) (Regulatory Guidelines). Pretoria: National Energy Regulator of South Africa.

National Energy Regulator of South Africa (NERSA). (2009b). Renewable Energy Regulatory Feed-In (Tariff Guidelines). Pretoria: National Energy Regulator of South Africa.

National Energy Regulator of South Africa (NERSA). (2009c). National Energy Regulator of South Africa Consultation Paper: Renewable Energy Feed-In Tariff Phase 2 July 2009. National Energy Regulator of South Africa, Pretoria. (Consultation Paper)

National Energy Regulator of South Africa (NERSA). (2011). Review of Renewable Energy Feed-In Tariffs. National Energy Regulator of South Africa, Pretoria. (Consultation Paper)

Parsons, W. (1995). Public Policy: An Introduction to the Theory and Practice of Policy Analysis. Cheltenham: Edward Elgar.

Pickering, M. (2013). Renewable Energy: Assessing the Experience of South Africa's Renewable Energy Independent Power Producer Procurement Programme (REIPPPP).

Stemple, R. (2013). Sustainable Growth from a Renewable Source. Futuregrowth Asset Management.

Steyn, G. (2013). Response to TIPS presentation on "Review of Regulators' Orientation and Performance: Electricity." 
Unlimited Energy (2013). Renewable Energy Policy Mapping Study of the Republic of South Africa. Deutsche Gesellschaft für Internationale Zusammenarbeit (GIZ) and Pretoria: Department of Energy.

Yelland, C. (2009). Independent Power Producers (IPPs) Organise Collectively to Take on દskom. દદ Publishers. 